\title{
ASYMMETRIC DOUPOLY COMPETITION WITH INNOVATION SPILLOVER AND INPUT CONSTRAINTS
}

\author{
You-hua CHEN ${ }^{1}$, Pu-yan NIE ${ }^{2}$, X. Henry WANG 3 \\ ${ }^{1}$ College of Economics \& Management and Guangdong Center for Rural Economic Studies, \\ South China Agricultural University, 510642, Guangzhou, P.R. China \\ ${ }^{2}$ Guangdong University of Finance \& Economics, Guangzhou, 510320,P.R.China \\ ${ }^{3}$ Department of Economics, University of Missouri-Columbia, USA \\ E-mails:1'chenyhua214@163.com; ${ }^{2}$ pynie2013@163.com (corresponding author); \\ 3wangx@missouri.edu
}

Received 27 February 2013; accepted 03 July 2013

\begin{abstract}
This paper subjects to examine how technology spillover affects input competition and how input constraints impact firm innovation by a two-stage game model and theoretic analysis. The results show that with low spillover, the high cost firm can capture more input than the low cost firm through cost-reducing innovation. Adding input increases firms' innovation, but it cannot improve the disadvantaged firm's state under input constraint. Compared with non-cooperative innovation, cooperative innovation reduces innovation difference and firm size difference. The research implications are that disadvantage firms could take innovation spillover and capacity constraints as a competition strategy to obtain competition advantage and regulators should stimulate cooperative innovation to higher social welfare. The major value of this paper is that it combines capacity constraints and innovation investment originality.
\end{abstract}

Keywords: cost reducing innovation, input constraints, asymmetric competition, technology spillover, game theory, strategic effects.

JEL Classification: C72, D24, L13.

\section{Introduction}

Capacity constraints are common in many industries. Arenas and cinemas have only limited number of seats, and airports can only land limited number of airplanes. Firms sustain capacity constraints such as finance constraints (Love 2003; Whited 2006; Sena 2006; Carvajal et al. 2012), cash flow constraints (Kaplan, Zingales 2000), space constraints (Lester 2011), energy constraints (Veit et al. 2011), or information constraints (Ramadorai 2013). Capacity constraints change firms' competition strategy. On one hand, constraints restrict performance and development of the firm. On the other hand, firms can also obtain strategic advantages from constraints (Riordan 2003; Khanna, Schroder 2010). For example, Deng and Yano (2006) showed that the firm with tight capacity constraints will adopt more aggressive price. 
In recent years, capacity constraints have received much attention (e.g. Sena 2004; Whited 2006; Adilov 2012; Van Den Berg et al. 2012; Ramadorai 2013). All these studies can be classified into four areas generally. Firstly, some have investigated the effects of capacity constraints on prices. For example, Ishibashi (2008) studied collusive price equilibrium with capacity constraints and showed that capacity constraints heighten collusive leadership price. More interestingly, Arnold and Saliba (2011) implied capacity constraints yield price dispersion and high constrained firm charges high price. Secondly, some prior researches focused on the relationships between capacity constraints and output or industrial structure. Nie and Chen (2012) investigated duopoly competition with input constraints. They declared that input constraints reduce market size difference and price difference. Esó et al. (2010) obtained similar results and they concluded that capacity constraints lead to industry symmetry.

Part of the existent studies highlighted the effects of capacity constraints on other competition strategies such as merger and collusion. Froeb et al. (2003) studied the effects of mergers among firms facing capacity constraints. Taking dynamic aspects of competition into account, Compte et al. (2002) investigated the effects of capacity constraints on mergers and collusion.Van Den Berg et al. (2012) discussed capacity constraints under dynamic Cournot competition and considered the effects of capacity constraints on equilibrium while Froeb et al. (2003) and Chowdhury (2009) analyzed capacity constraints under Bertrand competition. These studies show that capacity constraints induce industrial symmetry. Fourthly, there are also a few studies of capacity constraints inparticular industries such as service providers (Burkart et al. 2012; Wang, Dragahi 2013), retail stores (Murray et. al 2012) and air transportation (Evans, Schaefer 2011). Genc and Reynolds (2010) identified how capacity constraints affect output equilibrium with wholesale electricity markets, and they also found that capacity constraints result in symmetry. Besides, Inderst and Wambach (2001) analyzed competitive insurance markets with limited capital.

For one thing, among the existing researches of capacity constraints, none takes innovation (or R\&D investment) into account despite its obvious significance. For example, energy-dependent firms should invest in innovation to promote its efficiency because of the scarcity of energy resources. Different from other studies, we consider innovation behavior with capacity constraints. The main purpose of this paper is to examine how technology spillover affects input competition and how input constraints affect firm innovation. We find that the conclusion drawn by prior studies such as Esó et al. (2010) and Nie and Chen (2012) that capacity constraints increase symmetry is not necessarily robust. For another thing, different from the major studies about cost reducing innovations of D'Aspremont and Jacquemin (1988) and Suzumura (1992), we investigate innovation with asymmetric firms and obtain some interesting conclusions. Firstly, spillover has a major effect on duopoly competition. Large spillover aggravates the high cost firm's status. But if spillover is small, the high cost firm can even obtain a competitive edge through innovation. Including innovation, we find input constraints increase firm symmetry only when spillover is low. Secondly, innovations of both firms increase as the input constraint bound increases. But increase in input constraint bound does not change the differences of innovation and firm size, because competitive firms 
divide increments equally. Finally, cooperative innovation mitigates innovation difference and firm size difference.

The rest of this paper is organized as follows. Based on some assumptions, the basic model is established in Section 1. Then we analyze the model under different conditions in Sections 2 and 3. Some discussions of the main conclusions are expounded in the last Section.

\section{Setup}

Two firms, denoted $i \in\{1,2\}$, with a constrained input and asymmetric costs produce perfectly substituting products. Denote the only input by $r_{i}$ for $i \in\{1,2\}$. Furthermore, $R>0$ represents the total capacity in this industry or $r_{1}+r_{2} \leq R$. Each firm transforms one unit input into one unit output efficiently, but with asymmetric costs ${ }^{1}$. The two firms produce homogenous products or product substitutability $\gamma=1^{2}$. And both of them launch R\&D investments with spillover $\beta \in[0,1]$ to reduce their costs before output decisions, which means we consider a two-stage model $^{3}$. Besides, we assume spillovers are symmetric between producers.

Let $p$ denote the price, $q_{1}$ and $q_{2}$ the outputs of the two firms. As in Liu and Wang (2013), Sacco and Schmutzer (2011) or Liu et al. (2011), the inverse demand function of our study is given by the following:

$$
p=A-q_{1}-q_{2} \text {. }
$$

Both firms produce with the only input $r_{i}$ efficiently, which means:

$$
q_{i}=r_{i}
$$

Denote firm 1 the low cost firm and firm 2 the high cost firm. Then the cost function with cost reducing innovation is given as the following:

$$
C_{i}=\left(c_{i}=x_{i}-\beta x_{j}\right) r_{i} .
$$

In (3), $x_{i}$ and $x_{j}$ are the R\&D investments of firm $i$ and $j$ for $i, j \in\{1,2\}$. Without loss of generality, we assume $c_{1}=c_{0}$ and $c_{2}=c_{0}+\tau$ are the initial unit costs of firms 1 and 2 , where the constant $\tau>0$ represents the cost difference or market power ${ }^{4}$. Cost of investment is quadratic, which is also employed by D'Aspremont and Jacquemin (1988), and Sacco and Schmutzer (2011). So the input-constrained producer i's profit maximization problem is:

$$
\begin{array}{ll}
\underset{r_{i}}{\operatorname{Max}} & \pi=\left(A-r_{i}-r_{j}\right) r_{i}-\left(c_{i}=x_{i}-\beta x_{j}\right) r_{i}-\frac{1}{2} x_{i}^{2}, \\
\text { S.T. } & r_{i}+r_{j}<R .
\end{array}
$$

\footnotetext{
${ }^{1}$ Considering that cost different already represents efficiency difference, we ignore the transform efficiency difference $\theta_{i}, i \in\{1,2\}$ of Nie and Chen (2012).

${ }^{2}$ Many studies investigated the relationship between substitutability and innovation (e.g. Holmes et al. 2012; Nie and Chen 2012; Sacco and Schumtzer 2011; Aghion et al. 2005). Like D'Aspremont and Jacquemin (1988), we only consider the situation that $\gamma=1$.

${ }^{3}$ Firms invest cost reducing innovation at the first stage and then make output decision at the second stage.

${ }^{4}$ See in Nie and Chen (2012).
} 
To ensure that both firms' inputs and investments are positive, the following assumption is necessary.

Assumption: $\tau<c_{0}$ and $R \leq A$.

This assumption means that the cost difference between firms should not be too large or the high cost firm will be forced to exit the market and that input constraints should be less than the largest market size. If input constraint is tight, then $r_{i}+r_{j}=R$. From equation (1), we get $r_{i}+r_{j}<A$. Then, we know that $R \leq A$.

The two firms play a two-stage game. At the first stage, they decide their best R\&D investments simultaneously and then decide their output simultaneously at the second stage. All equilibrium solutions are obtained by backward induction. In what follows, we analyze our model both under non-cooperative innovation and undercooperative innovation ${ }^{5}$.

\section{Non-cooperative innovation competition}

The Lagrangian function of firm i's profit maximization problem is:

$$
L_{i}=\left(A-r_{i}-r_{j}\right) r_{i}-\left(c_{i}-x_{i}-\beta x_{j}\right) r_{i}-\frac{1}{2} x_{i}^{2}+\lambda_{i}\left(R-r_{i}-r_{j}\right) .
$$

Case 1: Non-binding constraint. Non-binding constraint means $r_{1}+r_{2}<R$ and $\lambda_{1}=\lambda_{2}=0$. We analyze the model by backward induction. Given innovation levels at the first stage, solving function (5) we get the equilibrium outputs in the second stage, given as:

$$
\begin{aligned}
& r_{1}=\frac{A-c_{0}+\tau+(2-\beta) x_{1}+(2 \beta-1) x_{2}}{3}, \\
& r_{2}=\frac{A-c_{0}-2 \tau+(2 \beta-1) x_{1}+(2-\beta) x_{2}}{3} .
\end{aligned}
$$

Substituting (6) and (7) into (5), we obtain the optimal R\&D investments at the first stage, given as:

$$
\begin{gathered}
x_{1}=\frac{(4-2 \beta)\left[\left(A-c_{0}\right)\left(1-6 \beta+2 \beta^{2}\right)-\left(3-4 \beta+2 \beta^{2}\right) \tau\right]}{\left(1-6 \beta+2 \beta^{2}\right)\left(5-2 \beta+2 \beta^{2}\right)}, \\
x_{2}=\frac{(4-2 \beta)\left[\left(A-c_{0}\right)\left(1-6 \beta+2 \beta^{2}\right)+2(1+\beta) \tau\right]}{\left(1-6 \beta+2 \beta^{2}\right)\left(5-2 \beta+2 \beta^{2}\right)} .
\end{gathered}
$$

From (8) and (9) we draw the following conclusions.

\footnotetext{
${ }^{5}$ The second-mover firm will be forced to exit the market by the first-mover firm under input constraints Stackelberg competition if $\gamma=1$. So we ignore leader-follower competition.

${ }^{6}$ Denote $\varepsilon$ as a small constant. Then there exists a small range $\left[\frac{3-\sqrt{7}}{2}-\varepsilon, \frac{3-\sqrt{7}}{2}+\varepsilon\right]$ makes $x_{1}<0$. That means if $\beta \in\left[\frac{3-\sqrt{7}}{2}-\varepsilon, \frac{3-\sqrt{7}}{2}+\varepsilon\right]$, then $x_{1}$ should be equal to 0 and $x_{i}=0$ is beyond our study, so $\beta \notin\left[\frac{3-\sqrt{7}}{2}-\varepsilon, \frac{3-\sqrt{7}}{2}+\varepsilon\right]$.
} 
Proposition 1. Denote $\bar{\beta}_{1}$ as a constant given in the appendix. (i) When $\beta<\bar{\beta}_{1}, x_{1}$ decreases while $x_{2}$ increases with $\tau$. (ii). When $\beta>\bar{\beta}_{1}, x_{1}$ increases while $x_{2}$ decreases with $\tau^{7}$.

Proof: See the appendix.

Remarks. Proposition 1 shows that the spillover of innovation plays a major role in innovation competition. If spillover is small, the cost disadvantaged firm can mitigate its disadvantage by innovation. The larger the cost disadvantage, the stronger the innovation incentive for the disadvantaged firm. But if the spillover is larger than $\bar{\beta}$, the relationship between cost difference and innovation of the duopoly will reverse. Note that if $\tau=0$, our conclusions are the same as D'Aspremont and Jacquemin (1988), which means their study is a special case of ours.

Combining (8) with (9), we obtain the investment difference $\Delta x$ (or $\left|x_{1}-x_{2}\right|$ ) and total investments $\Sigma x$ (or $\left.\left|x_{1}+x_{2}\right|\right)$ easily, as given by:

$$
\begin{gathered}
\Delta x=\frac{(4-2 \beta) \tau}{6 \beta-1-2 \beta^{2}}, \\
\Sigma x=\frac{2(2-\beta)\left(2 A-\tau-2 c_{0}\right)}{5-2 \beta+2 \beta^{2}} .
\end{gathered}
$$

Then we achieve the following proposition.

Proposition 2. (i) $x_{1}<x_{2}$ if $\beta<\bar{\beta}_{1}$ and $x_{1}>x_{2}$ if $\beta>\bar{\beta}_{1}$. (ii) $\tau$ enlarges $\Delta x$,

$$
\begin{aligned}
& \left\{\begin{array} { l } 
{ \frac { \partial \Delta x } { \partial \beta } > 0 , \quad 0 \leq \beta < \frac { 3 - \sqrt { 7 } } { 2 } } \\
{ \frac { \partial \Delta x } { \partial \beta } < 0 , \quad \frac { 3 - \sqrt { 7 } } { 2 } < \beta \leq 1 }
\end{array} \text { and } \left\{\begin{array}{ll}
\frac{\partial^{2} \Delta x}{\partial \beta \partial \tau}>0, & 0 \leq \beta<\frac{3-\sqrt{7}}{2} \\
\frac{\partial^{2} \Delta x}{\partial \beta \partial \tau}<0, & \frac{3-\sqrt{7}}{2}<\beta \leq 1
\end{array} \text {. (iii) } \frac{\partial \Sigma x}{\partial \tau}<0, \frac{\partial \Sigma x}{\partial \beta}<0\right.\right. \\
& \text { and } \frac{\partial^{2} \Sigma x}{\partial \tau \partial \beta}>0 .
\end{aligned}
$$

Proof: See the appendix.

Remarks. Proposition 2 shows that the high cost firm innovates more if spillover is small, while the low cost firm innovates more if spillover is large. In other words, small spillover stimulates the high cost firm's innovation while high spillover stimulates the low cost firm's innovation. But the increase of spillover inhibits total innovation which is consistent with reality. Externality is harmful for innovation, so our society needs patent protection to protect the profits of innovating firms. On the one hand, cost difference, which also is regarded as market power (Nie and Chen 2012), enlarges innovation difference. On the other hand, cost difference reduces total innovation. These results show that monopoly inhibits innovation. Part (ii) of Proposition 2

$\overline{7 \bar{\beta}_{1}=\frac{3-\sqrt{7}}{2}}$ is the root of $1-6 \beta+2 \beta^{2}=0$. 
illustrates that cost difference boosts the relationship of spillover and innovation difference because $\operatorname{sign}\left\{\frac{\partial \Delta x}{\partial \beta}\right\}=\operatorname{sign}\left\{\frac{\partial^{2} \Delta x}{\partial \beta \partial \tau}\right\}$ and part (iii) of Proposition 2 shows that cost difference attenuates the relationship of spillover and total innovation because $\operatorname{sign}\left\{\frac{\partial \Sigma x}{\partial \beta}\right\}=-\operatorname{sign}\left\{\frac{\partial^{2} \Sigma x}{\partial \beta \partial \tau}\right\}$.

Substituting (8) and (9) back into (5) and solving obtains the final expressions of the equilibrium input of the two firms is given by:

$$
\begin{gathered}
r_{1}=\frac{3\left(1-6 \beta+2 \beta^{2}\right)\left(A-c_{0}\right)-3\left(3-4 \beta+2 \beta^{2}\right) \tau}{\left(1-6 \beta+2 \beta^{2}\right)\left(5-2 \beta+2 \beta^{2}\right)}, \\
r_{2}=\frac{3\left(1-6 \beta+2 \beta^{2}\right)\left(A-c_{0}\right)+6(1+\beta) \tau}{\left(1-6 \beta+2 \beta^{2}\right)\left(5-2 \beta+2 \beta^{2}\right)}
\end{gathered}
$$

and the input difference is given by:

$$
\Delta r=\left|\frac{3 \tau}{6 \beta-1-2 \beta^{2}}\right| .
$$

Differentiating expressions (12)-(14) with respect to $\tau$ and $\beta$, we acquire the following conclusions.

Proposition 3. (i) $r_{1}<r_{2}$ if $\beta<\bar{\beta}_{1}$ and $r_{1}>r_{2}$ if $\beta>\bar{\beta}_{1}$. (ii) When $\beta<\bar{\beta}_{1}, \frac{\partial r_{1}}{\partial \tau}<0, \frac{\partial r_{2}}{\partial \tau}>0$ and $\frac{\partial \Delta r}{\partial \tau}<0$. When $\beta>\bar{\beta}_{1}, \frac{\partial r_{1}}{\partial \tau}>0, \frac{\partial r_{2}}{\partial \tau}<0$ and $\frac{\partial \Delta r}{\partial \tau}>0$. (iii) $\frac{\partial \Delta r}{\partial \beta}<0$ and $\frac{\partial^{2} \Delta r}{\partial \beta \partial \tau}<0$.

Proof: See the appendix.

Remarks. It is a general conclusion that the cost advantaged firm produces more than its cost disadvantaged competitors. But interestingly, Proposition 3 shows that if innovation spillover is small, the disadvantaged incumbent can improve its status or even obtain an advantage by innovation. Proposition 3 also indicates that the relationship between cost difference and output depends on innovation spillover. High innovation spillover is beneficial to the high cost firm because spillover decreases input difference. More interestingly, the increase of cost difference reduces the effect of spillover on input difference.

Case 2. Tight constraint. Tight constraint means $r_{1}+r_{2}+R$ and $\lambda_{1}>0, \lambda_{1}>0$. To simplify the analysis, we further assume that $\lambda_{1}=\lambda_{2}$, which means the shadow prices of inputs of the two firms are the same. From Equation (5), we have:

$$
\begin{aligned}
& r_{1}^{*}=\frac{R+\tau+(1-\beta)\left(x_{1}^{*}-x_{2}^{*}\right)}{2}, \\
& r_{2}^{*}=\frac{R-\tau-(1-\beta)\left(x_{1}^{*}-x_{2}^{*}\right)}{2} .
\end{aligned}
$$

Comparing (15) and (16) with (6) and (7), we find that without innovation $\left(r_{1}^{*}-r_{2}^{*}\right)$ is exactly equal to $\left(r_{1}-r_{2}\right)$. Substituting $r_{1}^{*}$ and $r_{2}^{*}$ into (5), we have: 


$$
\begin{gathered}
x_{1}^{*}=\frac{\left(\beta-4 \beta^{2}+\beta^{3}\right) R+\left(A-c_{0}\right)\left(1-5 \beta+5 \beta^{2}-\beta^{3}\right)-\left(2-3 \beta+4 \beta^{2}-\beta^{3}\right) \tau}{\left(1+\beta^{2}\right)\left(1-4 \beta+\beta^{2}\right)}, \\
x_{2}^{*}=\frac{\left(\beta-4 \beta^{2}+\beta^{3}\right) R+\left(A-c_{0}\right)\left(1-5 \beta+5 \beta^{2}-\beta^{3}\right)+\left(1+2 \beta-\beta^{2}\right) \tau}{\left(1+\beta^{2}\right)\left(1-4 \beta+\beta^{2}\right)} .
\end{gathered}
$$

So the innovation difference and total innovation are:

$$
\begin{gathered}
\Delta x^{*}=\left|\frac{(3-\beta) \tau}{1-4 \beta+\beta^{2}}\right|, \\
\Sigma x^{*}=\frac{2 \beta R+2(1-\beta)\left(A-c_{0}-\frac{1}{2} \tau\right)}{1+\beta^{2}} .
\end{gathered}
$$

Then the optional inputs and the difference of inputs are given by:

$$
\begin{gathered}
r_{1}^{*}=\frac{\left(1-4 \beta+\beta^{2}\right) R-2 \tau}{2\left(1-4 \beta+\beta^{2}\right)}, \\
r_{2}^{*}=\frac{\left(1-4 \beta+\beta^{2}\right) R+2 \tau}{2\left(1-4 \beta+\beta^{2}\right)}, \\
\Delta r^{*}=\left|\frac{2 \tau}{1-4 \beta+\beta^{2}}\right| .
\end{gathered}
$$

From (17)-(23), we obtain the following conclusions.

Proposition 4. All propositions under non-binding constraint hold in tight constraint situation.

Proof: From the proofs of Propositions 1 to 3 we can get the conclusions of Proposition 4 by straightforward calculations 9 .

Remarks. Proposition 4 shows that all the conclusions above are robust. There also exists $\bar{\beta}_{2}$ such that $r_{1}^{*}>r_{2}^{*}$ when $\beta<\bar{\beta}_{2}$, and $r_{1}^{*}<r_{2}^{*}$ when $\beta>\bar{\beta}_{2}{ }^{10}$. But $\bar{\beta}_{1}<\bar{\beta}_{2}$, which means comparing with non-tight constraints, in tight constraints circumstance the cost disadvantaged firm has more chance to plunder more input or market share than its competitor. In other words, the high cost firm benefits from input constraints. Different from innovation, inputs of the firms are only decided by $\mathrm{R}, \tau$ and $\beta$. Maximum market size $\mathrm{A}$ and basic cost $c_{0}$ have no effect on input.

Proposition 5. $\frac{\partial x_{1}^{*}}{\partial R}>0, \frac{\partial x_{2}^{*}}{\partial R}>0, \frac{\partial \Sigma x^{*}}{\partial R}>0$ and $\frac{\partial r_{1}^{*}}{\partial R}=\frac{\partial r_{2}^{*}}{\partial R}=\frac{1}{2}$.

\footnotetext{
${ }^{8}$ Denote $\varepsilon$ a small constant, then there exists a small range $[2-\sqrt{3}-\varepsilon, 2-\sqrt{3}+\varepsilon]$ in which $x_{1}<0$. Which means if $\beta \in[2-\sqrt{3}-\varepsilon, 2-\sqrt{3}+\varepsilon]$, then $x_{1}$ should be equal to $0 . x_{i}^{*}=0$ is out of our study, so $\beta \notin[2-\sqrt{3}-\varepsilon, 2-\sqrt{3}+\varepsilon]$.
}

${ }^{9}$ For more details of the proof, please see Table 1 in the appendix.

${ }_{10} \overline{\beta_{1}}=\frac{3-\sqrt{7}}{2} \approx 0.177$ and $\overline{\beta_{2}}=2-\sqrt{3} \approx 0.268$, so we get $\overline{\beta_{1}}<\overline{\beta_{2}}$ easily. $\overline{\beta_{2}}$ is the root of $1-4 \beta+\beta^{2}=0$. 


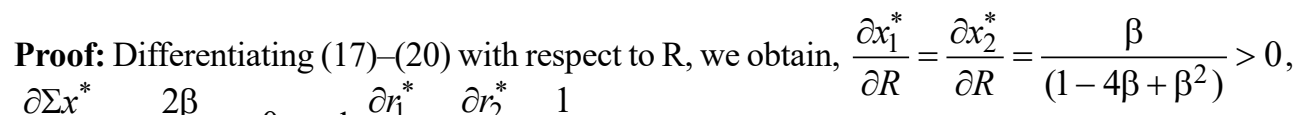
$\frac{\partial \Sigma x^{*}}{\partial R}=\frac{2 \beta}{1+\beta^{2}}>0$ and $\frac{\partial r_{1}^{*}}{\partial R}=\frac{\partial r_{2}^{*}}{\partial R}=\frac{1}{2}$.

Conclusions are therefore achieved and the proof is complete.

Remarks. Proposition 5 reveals that, as R increases, innovation of firms, total innovation and output of the industry increase. And both the increase rate of innovation and output of the firms are the same. More interestingly, innovation of the firm has nothing to do with $\mathrm{R}$ if spillover is equal to 0 or no innovation spillover. Furthermore, any incremental input will be divided by the two firms equally, which means increasing input resources of the constrained industry cannot improve the status of the cost disadvantaged producer or firm size difference has nothing to do with the increase of $\mathrm{R}$.

Proposition 6. Total innovation, innovation difference and input difference under different

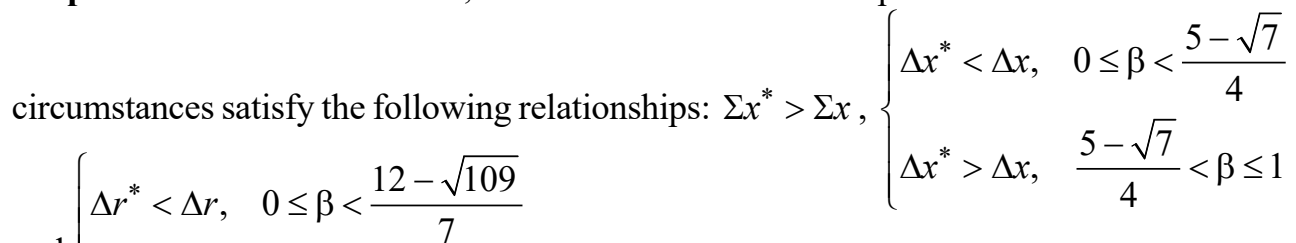
and

$$
\Delta r^{*}>\Delta r, \quad \frac{12-\sqrt{109}}{7}<\beta \leq 1
$$

Proof: See the appendix.

Remarks. Esó et al. (2010) indicated that capacity constraints lead to industrial symmetry and our conclusion is the same as theirs if spillover $\beta$ is equal to 0 . But Proposition 6 implies that if duopoly competes with innovation and innovation has spillover, capacity constraints do not necessarily result in symmetry. Furthermore, capacity constraints even increase industrial asymmetry if innovation spillover is high.

\section{Cooperative innovation}

Prior studies have showed that cooperative innovation makes things different (D'Aspremontand Jacquemin 1988; Suzumura 1992; Erkal, Piccinin 2010). Next we analyze our model under cooperative innovation. Cooperative innovation means firms decide their optimal equilibrium innovations based on the joint profit maximization problem. Two firms make innovation decisions based on joint profit maximization at the first stage and then decide their outputs separately at the second stage. Here we also use backward induction to solve the problem. Denote the joint profit function as $\pi_{1}+\pi_{2}=f\left[r_{1}, r_{2}, x_{1}, x_{2}\right], i=(1,2)$. $r_{i}\left(x_{i}, x_{j}\right)$ and $x_{i}$ are the output and innovation of firm $i, i=(1,2)$. Then optional equilibrium innovation is given by:

$$
x_{i}=\arg \max \left(\pi_{1}+\pi_{2}\right) f\left[r_{1}, r_{2}, x_{1}, x_{2}\right], i=(1,2) .
$$


Case 1. Non-binding constraints. Solving (24), we get:

$$
\begin{gathered}
x_{1}^{c}=\frac{2\left[\left(1-3 \beta-2 \beta^{2}+2 \beta^{3}\right)\left(A-c_{0}\right)-\left(4-7 \beta+2 \beta^{2}\right) \tau\right]}{7-32 \beta+28 \beta^{2}-4 \beta^{4}}, \\
x_{2}^{c}=\frac{2\left[\left(1-3 \beta-2 \beta^{2}+2 \beta^{3}\right)\left(A-c_{0}\right)+\left(3-4 \beta+2 \beta^{2}\right) \tau\right]}{7-32 \beta+28 \beta^{2}-4 \beta^{4}}, \\
\Delta x^{c}=\left|\frac{2(1-\beta) \tau}{1-4 \beta+2 \beta^{2}}\right| \\
\Sigma x^{c}=\frac{2(1+\beta)\left(2 A-2 c_{0}-\tau\right)}{7-4 \beta-2 \beta^{2}} .
\end{gathered}
$$

In the model of D'Aspremontand and Jacquemin (1988), $x_{1}^{c}$ is equal to $x_{2}^{c}$ and $\Delta x^{c}=0$ because they did not consider cost difference $\tau$. If $\tau=0$, we also have $x_{1}^{c}=x_{2}^{c}$ and $\Delta x^{c}=0$, and our conclusions are the same as D'Aspremont and Jacquemin (1988).

Substituting (25) and (26) into (6) and (7), we have:

$$
\begin{gathered}
r_{1}^{c}=\frac{3\left(1-4 \beta+2 \beta^{2}\right)\left(A-c_{0}\right)+\left(5-8 \beta+2 \beta^{2}\right) \tau}{7-32 \beta+28 \beta^{2}-4 \beta^{4}}, \\
r_{2}^{c}=\frac{3\left(1-4 \beta+2 \beta^{2}\right)\left(A-c_{0}\right)-2\left(1+2 \beta-2 \beta^{2}\right) \tau}{7-32 \beta+28 \beta^{2}-4 \beta^{4}}, \\
\Delta r^{c}=\left|\frac{\tau}{1-4 \beta+2 \beta^{2}}\right| .
\end{gathered}
$$

Case 2. Tight constraints. Optimal equilibrium innovations are given by:

$$
\begin{aligned}
& x_{1}^{c^{*}}=\frac{\left(1-3 \beta-2 \beta^{2}+2 \beta^{3}\right) R-2(1-\beta) \tau}{2-8 \beta+4 \beta^{2}}, \\
& x_{2}^{c^{*}}=\frac{\left(1-3 \beta-2 \beta^{2}+2 \beta^{3}\right) R+2(1-\beta) \tau}{2-8 \beta+4 \beta^{2}} .
\end{aligned}
$$

Then innovation difference and total innovation are:

$$
\begin{gathered}
\Delta x^{c^{*}}=\left|\frac{2(1-\beta) \tau}{1-4 \beta+2 \beta^{2}}\right|, \\
\Sigma x^{c^{*}}=(1+\beta) R .
\end{gathered}
$$

Combining (15), (16), (32) and (33), we obtain equilibrium inputs and input difference:

$$
\begin{gathered}
r_{1}^{c^{*}}=\frac{\left(1-4 \beta+2 \beta^{2}\right) R-\tau}{2\left(1-4 \beta+2 \beta^{2}\right)}, \\
r_{2}^{c^{*}}=\frac{\left(1-4 \beta+2 \beta^{2}\right) R+\tau}{2\left(1-4 \beta+2 \beta^{2}\right)}, \\
\Delta r^{c^{*}}=\left|\frac{\tau}{1-4 \beta+2 \beta^{2}}\right| .
\end{gathered}
$$


All the conclusions under non-cooperative innovation are still valid under cooperativeinnovation. Moreover, comparing the results of cooperative innovation with those of noncooperative innovation, we have the following conclusions.

Proposition 7. $\Delta x^{c}=\Delta x^{c^{*}}$ and $\Delta r^{c}=\Delta r^{c^{*}}$.

Proof: From equation (27), (31), (34) and (38), we get $\Delta x^{c^{*}}=\left|\frac{2(1-\beta) \tau}{1-4 \beta+2 \beta^{2}}\right|=\Delta x^{c}$, $\Delta r^{c^{*}}=\left|\frac{\tau}{1-4 \beta+2 \beta^{2}}\right|=\Delta r^{c}$.

Conclusions are therefore achieved and the proof is complete.

Remarks. Proposition 7 shows that if firms make cooperative innovation decisions, no matter input constraint is tight or not, the differences of innovation and input are the same.

Proposition 8. Innovation and input difference and total innovation of non-cooperative and cooperative meet the following relationship: $\Delta x^{c}<\Delta x, \Delta x^{c^{*}}<\Delta x^{*}, \Delta r^{c}<\Delta r$, $\Delta r^{c^{*}}<\Delta r,\left\{\begin{array}{ll}\Sigma x^{c} \leq \Sigma x, & 0<\beta<\frac{1}{2} \\ \Sigma x^{c} \geq \Sigma x, & \frac{1}{2}<\beta \leq 1\end{array}\right.$ and $\left\{\begin{array}{ll}\Sigma x^{c *} \leq \Sigma x^{*}, & 0 \leq \beta \leq \bar{\beta} \\ \Sigma x^{c^{*}} \geq \Sigma x^{*}, & \bar{\beta}<\beta \leq 1\end{array}\right.$.

Proof: See in appendix.

Remarks. Cooperative innovation always reduces the difference of inputs (or firm size), but cooperative innovation increases total innovation if spillover is large. If spillover is small, comparing with non-cooperative innovation, cooperative innovation inhibits total innovation. The results above illustrate that the disadvantaged firm always benefits from cooperative innovation, but things for the advantaged firm and consumers are ambiguous. Our research partly explains the phenomenon that non-cooperative innovation and cooperative innovation coexist. Because spillovers of innovation are different, firms take different innovation strategies (cooperative innovation or non-cooperative innovation) under which they carry out different innovation. The breakpoint $\bar{\beta}$ in Proposition 8 is dependent on the relationship of $\mathrm{R}$ and $\left(A-c_{0}-\frac{1}{2} \tau\right)$.

\section{Discussion and conclusions}

In this study, we investigate how innovation spillover affects input competition and how cost difference, spillover and capacity constraints affect innovation with input constraints under Cournot competition. Different from earlier study, our study shows that even when cooperative innovation strategies are adopted by firms, both input and innovation of different firms are not the same due to the existence of cost difference. Prior studies illustrated that capacity constraints lead to symmetric firms, which means capacity constraints reduce the high cost firm's disadvantage. Our study shows that the high cost firm can even acquire competition advantage or plunder more input than the low cost firm by cost-reducing innovation under low spillover condition. But high innovation spillover enlarges the input difference between firms and high spillover inhibits innovation investment of high cost firm. Increasing total 
input change nothings because any unit increase input will be divided equally by the two firms. Interestingly, the increase of constraints bound raises innovation.

The conclusion reached by early studies that cooperative innovation results in symmetric innovation is not a general conclusion if firms compete with asymmetric costs, but cooperative innovation reduces input difference and innovation difference. Although cooperative innovation reduces innovation and input difference, it increases total innovation under high innovation spillover and consumers do not always benefit from cooperative innovation. Furthermore, this study reveals that the high cost firm prefers low innovation spillover, while the low cost firm prefers high spillover.

This paper combines capacity constraints and innovation investment originality. In other words, we offer a valuable discussion about cost reducing innovation under capacity constraints, which expends the application of innovation theory. The major research implications are that disadvantage firms could take innovation spillover and capacity constraints as a competition strategy to obtain competition advantage and regulators should stimulate cooperative innovation to higher social welfare. Besides, people should pay more attention to constrained input capacity because it has significant impact on competition and industrial development.

Comparing with some of the earlier studies, the model of this study is more general. This study only considers quantity-sensitive capacity constraints, while quality-sensitive capacity constraints in a more interesting issue. Another important market factor, product substitution also has major effect on output and innovation competition, so further study will include product substitutability and quality-sensitive capacity constraints. If products offered by different firms are not prefect substitutes, our study can be extended to Stackelberg competition.

\section{Acknowledgements}

This work was supported by the National Natural Science Foundation of PRC (71401057, 71271100), the Guangdong Social Science Foundation (GD13YLJ02), the Soft Science Project of Guangdong Province (2014A070704008), the Key Program of National Natural Science Foundation of China (71333004), the National Social Science Fund of PRC (14AJY020) and the China Scholarship Council Foundation (201508440104). Sincere thanks to the anonymous reviewers for their helpful suggestions.

\section{References}

Adilov, N. 2012. Strategic use of forward contracts and capacity constraints, International Journal of Industrial Organization 30(2): 164-173. http://dx.doi.org/10.1016/j.ijindorg.2011.08.001

Aghion, P.; Bloom, N.; Blundell, R.; Griffith, R.; Howitt, P. 2006. Competition and innovation: an inverted-U relationship, The Quarterly Journal of Economics 120(2): 701-728.

Arnold, M. A.; Saliba, C. 2011. Asymmetric capacity constraints and equilibrium price dispersion, Economics Letters 111(2): 158-160. http://dx.doi.org/10.1016/j.econlet.2011.02.014

Burkart, W. R.; Klein, R.; Mayer, S. 2012. Product line pricing for services with capacity constraints and dynamic substitution, European Journal of Operational Research 219(2): 347-359. http://dx.doi.org/10.1016/j.ejor.2011.12.026 
Carvajal, A.; Rostek, M.; Weretka, M. 2012. Competition in financial innovation, Econometrica 80(5): 1895-1936. http://dx.doi.org/10.3982/ECTA9837

Chowdhury, P. R. 2009. Bertrand competition with non-rigid capacity constraints, Economics Letters 103(1): 55-58. http://dx.doi.org/10.1016/j.econlet.2009.01.025

Compte, O.; Jenny, F.; Rey, P. 2002. Capacity constraints, mergers and collusion, European Economic Review 46(1): 1-29. http://dx.doi.org/10.1016/S0014-2921(01)00099-X

D'Aspremont, C.; Jacquemin, J. 1988. Cooperative and noncooperative R\&D in duopoly with spillover, American Economic Review 78: 1133-1137.

Deng, S. M.; Yano, C. A. 2006. Joint production and pricing decisions with setup costs and capacity constraints, Management Science 52(5): 741-756. http://dx.doi.org/10.1287/mnsc.1050.0491

Erkal, N.; Piccinin, D. 2010. Cooperative R\&D under uncertainty with free entry, International Journal of Industrial Organization 28(1): 74-85. http://dx.doi.org/10.1016/j.ijindorg.2009.07.003

Esó, P.; Nocke, V.; White, L. 2010. Competition for scarce resources, The RAND Journal of Economics 41(3): 524-548. http://dx.doi.org/10.1111/j.1756-2171.2010.00110.x

Evans, A.; Schaefer, A. 2011.The impact of airport capacity constraints on future growth in the US air transportation system, Journal of Air Transport Management 17(5): 288-295.

http://dx.doi.org/10.1016/j.jairtraman.2011.03.004

Froeb, L.; Tschantz, S.; Crooke, P. 2003. Bertrand competition with capacity constraints: mergers among parking lots, Journal of Econometrics 113(1): 49-67.

http://dx.doi.org/10.1016/S0304-4076(02)00166-5

Genc, T. S.; Reynolds, S. S. 2011. Supply function equilibria with capacity constraints and pivotal suppliers, International Journal of Industrial Organization 29(4): 432-442.

http://dx.doi.org/10.1016/j.ijindorg.2010.08.003

Holmes, T. J.; Levine, D. K.; Schmitz, J. A. 2012. Monopoly and the incentive to innovate when adoption involves switchover disruptions, American Economic Journal-Microeconomics 4(3): 1-33. http://dx.doi.org/10.1257/mic.4.3.1

Inderst, R.; Wambach, A. 2001. Competitive insurance markets under adverse selection and capacity constraints, European Economic Review 45(10): 1981-1992.

http://dx.doi.org/10.1016/S0014-2921(01)00101-5

Ishibashi, I. 2008. Collusive price leadership with capacity constraints, International Journal of Industrial Organization 26(3): 704-715. http://dx.doi.org/10.1016/j.ijindorg.2007.01.007

Khanna, N.; Schroder, M. 2010. Optimal debt contracts and product market competition with exit and entry, Journal of Economic Theory 145(1): 156-188.

http://dx.doi.org/10.1016/j.jet.2009.05.005

Kaplan, S. N.; Zingales, L. 2000. Investment-cash flow sensitivities are not valid measures of financing constraints, The Quarterly Journal of Economics 115(2): 707-712.

http://dx.doi.org/10.1162/003355300554782

Lester, B. 2011. Information and prices with capacity constraints, American Economic Review 101(4): 1591-1600. http://dx.doi.org/10.1257/aer.101.4.1591

Liu, L.; Wang, X. H. 2013. Entry bias and product substitutability, Journal of Institutional and Theoretical Economics 169(2): 304-319. http://dx.doi.org/10.1628/093245613X13609094777220

Liu, L.; Wang, X. H.; Yang, B. Z. 2011. Strategic choice of channel structure, Oligopoly Technique Reports WP-11-02. Department of Economics, University of Missouri.

Love, I. 2003. Financial development and financing constraints: international evidence from the structural investment model, Review of Financial Studies 16(3): 765-791.

http://dx.doi.org/10.1093/rfs/hhg013 
Murray, C. C.; Gosavi, A.; Talukdar, D. 2012. The multi-product price-setting newsvendor with resource capacity constraints, International Journal of Production Economics 138(1): 148-158. http://dx.doi.org/10.1016/j.ijpe.2012.03.014

Nie, P.; Chen, Y. 2012. Duopoly competition with capacity constrained input, Economic Modeling 29(5): 1715-1721. http://dx.doi.org/10.1016/j.econmod.2012.05.022

Ramadorai, T. 2013. Capacity constraints, investor information, and hedge fund returns, Journal of Financial Economics 107(2): 401-416. http://dx.doi.org/10.1016/j.jineco.2012.08.020

Riordan, M. 2003. How do capital markets influence product market competition, Review of Industrial Organization 23(3): 179-191. http://dx.doi.org/10.1023/B:REIO.0000031370.88761.7d

Sacco, D.; Schmutzer, A. 2011. Is there a U-shaped relation between competition and investment, International Journal of Industrial Organization 29(1): 65-73.

http://dx.doi.org/10.1016/j.ijindorg.2009.09.003

Sena, V. 2006. The determinants of firms performance: can finance constraints improve technical efficiency?, European Journal of Operational Research 172(1): 311-325.

http://dx.doi.org/10.1016/j.ejor.2004.07.071

Suzumura, K. 1992. Cooperative and noncooperative R\&D in an oligopoly with spillovers, The American Economic Review 82(5): 1307-1320.

Van Den Berg, A.; Bos, I.; Herings, P. J.-J.; Peters, H. 2012. Dynamic Cournot duopoly with intertemporal capacity constraints, International Journal of Industrial Organization 30(2): 174192. http://dx.doi.org/10.1016/j.ijindorg.2011.08.002

Veit, D. J.; Weidlich, A.; Krafft, J. A. 2011. An agent-based analysis of the German electricity market with transmission capacity constraints, Energy Policy 37(10): 4132-4144.

http://dx.doi.org/10.1016/j.enpol.2009.05.023

Wang, C.; Dragahi, F. 2013. Service customization under capacity constraints: an auction-based model, Journal of Intelligent Manufacturing 24(5): 1033-1045.

http://dx.doi.org/10.1007/s10845-012-0689-7

Whited, T. M. 2006. External finance constraints and the intertemporal pattern of intermittent investment, Journal of Financial Economics 81(3): 467-502.

http://dx.doi.org/10.1016/j.jfineco.2005.07.007

\section{APPENDIX}

Table 1. The relationships between variables and parameters

\begin{tabular}{c|c|c|c|c|c|c|c|c|c|c|c|c|c|c|c}
\hline & \multicolumn{2}{|c|}{$\partial t$} & \multicolumn{2}{|c|}{$\partial \beta$} & \multicolumn{2}{c|}{$\partial \beta \partial \tau$} & & $\partial R$ & \multicolumn{2}{|c|}{$\partial t$} & \multicolumn{2}{|c|}{$\partial \beta$} & \multicolumn{2}{|c}{$\partial \beta \partial \tau$} \\
\hline & $L^{a}$ & $S^{a}$ & $L^{a}$ & $S^{a}$ & $L^{a}$ & $S^{a}$ & & & $L^{b}$ & $S^{b}$ & $L^{b}$ & $S^{b}$ & $L^{b}$ & $S^{b}$ \\
$x_{1}$ & - & + & - & - & - & - & $x_{1}{ }^{*}$ & + & - & + & & & - & - \\
$x_{2}$ & + & - & & & + & + & $x_{2}{ }^{*}$ & + & + & - & & & + & + \\
$r_{1}$ & - & + & & & - & - & $r_{1}{ }^{*}$ & $1 / 2$ & - & + & - & - & - & - \\
$r_{2}$ & + & - & & & + & + & $r_{2}{ }^{*}$ & $1 / 2$ & + & - & + & + & + & + \\
$\Delta x$ & + & + & + & - & + & - & $\Delta x^{*}$ & 0 & + & + & + & - & + & + \\
$\Sigma x$ & - & - & - & - & + & + & $\Sigma x^{*}$ & + & - & - & & & + & + \\
$\Delta r$ & - & + & - & - & - & - & $\Delta r^{*}$ & 0 & - & + & - & - & - & - \\
\hline
\end{tabular}

Notes: $\mathrm{L}^{\mathrm{a}}$ and $\mathrm{S}^{\mathrm{a}}$ means $\beta<\frac{3-\sqrt{7}}{2}$ and $\beta>\frac{3-\sqrt{7}}{2}$, while $L^{b}$ and $S^{b}$ means $\beta<2-\sqrt{3}$ and $\beta>2-\sqrt{3}$. All the results are obtained by differentiated variables by parameters. 


\section{Proof of Proposition 1}

From (8), we have $\frac{\partial x_{1}}{\partial \tau}=\left\{\begin{array}{l}-\frac{(4-2 \beta)\left(3-4 \beta+2 \beta^{2}\right)}{\left(1-6 \beta+2 \beta^{2}\right)\left(5-2 \beta+2 \beta^{2}\right)}<0, \quad 0 \leq \beta<\frac{3-\sqrt{7}}{2} \\ -\frac{(4-2 \beta)\left(3-4 \beta+2 \beta^{2}\right)}{\left(1-6 \beta+2 \beta^{2}\right)\left(5-2 \beta+2 \beta^{2}\right)}>0, \quad \frac{3-\sqrt{7}}{2}<\beta \leq 1\end{array}\right.$ and

from (9) we have $\frac{\partial x_{2}}{\partial \tau}=\left\{\begin{array}{ll}\frac{4(2-\beta)(1+\beta)}{\left(1-6 \beta+2 \beta^{2}\right)\left(5-2 \beta+2 \beta^{2}\right)}>0, & 0 \leq \beta<\frac{3-\sqrt{7}}{2} \\ \frac{4(2-\beta)(1+\beta)}{\left(1-6 \beta+2 \beta^{2}\right)\left(5-2 \beta+2 \beta^{2}\right)}<0, & \frac{3-\sqrt{7}}{2}<\beta \leq 1\end{array}\right.$.

Conclusions are therefore achieved and the proof is complete.

From (8) easy to get $\left(x_{1}-x_{2}\right)=\left\{\begin{array}{ll}\frac{(4-2 \beta) \tau}{6 \beta-1-2 \beta^{2}}, & 0 \leq \beta<\frac{3-\sqrt{7}}{2} \\ \frac{(4-2 \beta) \tau}{6 \beta-1-2 \beta^{2}}, & \frac{3-\sqrt{7}}{2}<\beta \leq 1\end{array}\right.$,

$\frac{\partial \Delta x}{\partial \beta}=\left\{\begin{array}{ll}\frac{2\left(11-8 \beta+2 \beta^{2}\right) \tau}{\left(6 \beta-1-2 \beta^{2}\right)^{2}}>0, & 0 \leq \beta<\frac{3-\sqrt{7}}{2} \\ -\frac{2\left(11-8 \beta+2 \beta^{2}\right) \tau}{\left(6 \beta-1-2 \beta^{2}\right)^{2}}<0, & \frac{3-\sqrt{7}}{2}<\beta \leq 1\end{array}\right.$ and

$\frac{\partial^{2} \Delta x}{\partial \beta \partial \tau}=\left\{\begin{array}{ll}\frac{2\left(11-8 \beta+2 \beta^{2}\right)}{\left(6 \beta-1-2 \beta^{2}\right)^{2}}>0, & 0 \leq \beta<\frac{3-\sqrt{7}}{2} \\ -\frac{2\left(11-8 \beta+2 \beta^{2}\right)}{\left(6 \beta-1-2 \beta^{2}\right)^{2}}<0, & \frac{3-\sqrt{7}}{2}<\beta \leq 1\end{array}\right.$.

From equation (9), we achieve

$\frac{\partial\left(x_{1}+x_{2}\right)}{\partial \tau}=-\frac{2(2-\beta)}{5-2 \beta+2 \beta^{2}}<0$,

$\frac{\partial\left(x_{1}+x_{2}\right)}{\partial \beta}=-\frac{2\left(1+8 \beta-2 \beta^{2}\right)\left(2 A-\tau-2 c_{0}\right)}{\left(5-2 \beta+2 \beta^{2}\right)^{2}}<0$ and $\frac{\partial^{2}\left(x_{1}+x_{2}\right)}{\partial \beta \partial \tau}=\frac{2\left(1+8 \beta-2 \beta^{2}\right)}{\left(5-2 \beta+2 \beta^{2}\right)^{2}}>0$.

Conclusions are therefore achieved and the proof is complete.

\section{Proof of Proposition 3}

Subtract (12) by (13), we have $\left(r_{1}-r_{2}\right)=\left\{\begin{array}{ll}\frac{3 \tau}{6 \beta-1-2 \beta^{2}}<0, & 0 \leq \beta<\frac{3-\sqrt{7}}{2} \\ \frac{3 \tau}{6 \beta-1-2 \beta^{2}}>0, & \frac{3-\sqrt{7}}{2}<\beta \leq 1\end{array}\right.$.

to (14), we get 
$\frac{\partial r_{1}}{\partial \tau}=\left\{\begin{array}{l}-\frac{3\left(3-4 \beta+2 \beta^{2}\right)}{\left(1-6 \beta+2 \beta^{2}\right)\left(5-2 \beta+2 \beta^{2}\right)}<0, \quad 0 \leq \beta<\frac{3-\sqrt{7}}{2} \\ -\frac{3\left(3-4 \beta+2 \beta^{2}\right)}{\left(1-6 \beta+2 \beta^{2}\right)\left(5-2 \beta+2 \beta^{2}\right)}>0, \quad \frac{3-\sqrt{7}}{2}<\beta \leq 1\end{array}\right.$,
$\frac{\partial^{2} r_{1}}{\partial \beta \partial \tau}=-\frac{2\left(19-31 \beta+44 \beta^{2}-44 \beta^{3}+20 \beta^{4}-4 \beta^{5}\right)}{\left(1-6 \beta+2 \beta^{2}\right)^{2}\left(5-2 \beta+2 \beta^{2}\right)^{2}}<0$,

$\frac{\partial r_{2}}{\partial \tau}=\left\{\begin{array}{ll}\frac{6(1+\beta)}{\left(1-6 \beta+2 \beta^{2}\right)\left(5-2 \beta+2 \beta^{2}\right)}>0, & 0 \leq \beta<\frac{3-\sqrt{7}}{2} \\ \frac{6(1+\beta)}{\left(1-6 \beta+2 \beta^{2}\right)\left(5-2 \beta+2 \beta^{2}\right)}<0, & \frac{3-\sqrt{7}}{2}<\beta \leq 1\end{array}\right.$,

$\frac{\partial^{2} r_{2}}{\partial \beta \partial \tau}=\frac{6\left(37-48 \beta+24 \beta^{2}+16 \beta^{3}-12 \beta^{4}\right)}{\left(1-6 \beta+2 \beta^{2}\right)^{2}\left(5-2 \beta+2 \beta^{2}\right)^{2}}>0$,

$\frac{\partial \Delta r}{\partial \tau}=\left\{\begin{array}{l}\frac{3}{6 \beta-1-2 \beta^{2}}<0, \quad 0 \leq \beta<\frac{3-\sqrt{7}}{2} \\ \frac{3}{6 \beta-1-2 \beta^{2}}>0, \quad \frac{3-\sqrt{7}}{2}<\beta \leq 1\end{array}, \frac{\partial \Delta r}{\partial \beta}=-\frac{3(6-4 \beta) \tau}{\left(6 \beta-1-2 \beta^{2}\right)^{2}}<0\right.$ and

$\frac{\partial^{2} \Delta r}{\partial \beta \partial \tau}=-\frac{3(6-4 \beta)}{6 \beta-1-2 \beta^{2}}<0$.

Conclusions are therefore achieved and the proof is complete.

\section{Proof of Proposition 6}

It is easy to check that $\Sigma x^{*}-\Sigma x=\frac{\left(10 \beta-4 \beta^{2}+4 \beta^{3}\right) R+2(1-5 \beta)\left(A-c_{0}-0.5 \tau\right)}{\left(1+\beta^{2}\right)\left(5-2 \beta+2 \beta^{2}\right)}>0$ and $\left(\Delta x^{*}-\Delta x\right)= \begin{cases}-\frac{(1+\beta) \tau}{\left(1-4 \beta+\beta^{2}\right)\left(1-6 \beta+2 \beta^{2}\right)}, & 0 \leq \beta<\frac{3-\sqrt{7}}{2} \\ -\frac{\left(7-37 \beta+24 \beta^{2}-4 \beta^{3}\right) \tau}{\left(1-4 \beta+\beta^{2}\right)\left(1-6 \beta+2 \beta^{2}\right)}, & \frac{3-\sqrt{7}}{2}<\beta<2-\sqrt{3}, \text { so } \\ \frac{(1+\beta) \tau}{\left(1-4 \beta+\beta^{2}\right)\left(1-6 \beta+2 \beta^{2}\right)}, & 2-\sqrt{3}<\beta \leq 1\end{cases}$ $\left\{\begin{array}{ll}\Delta x^{*}<\Delta x, & 0 \leq \beta<\frac{5-\sqrt{7}}{4} \\ \Delta x^{*}>\Delta x, & \frac{5-\sqrt{7}}{4}<\beta \leq 1\end{array}\right.$. For the same reason we achieved 


$$
\left\{\begin{array}{l}
\Delta r^{*}<\Delta r, \quad 0 \leq \beta<\frac{12-\sqrt{109}}{7} \\
\Delta r^{*}>\Delta r, \quad \frac{12-\sqrt{109}}{7}<\beta \leq 1
\end{array}\right.
$$

Conclusions are therefore achieved and the proof is complete.

\section{Proof of Proposition 8}

We have $\Delta x^{c}=\left|\frac{2(1-\beta) \tau}{1-4 \beta+2 \beta^{2}}\right|$ and $\Delta x=\left|\frac{2(2-\beta) \tau}{1-6 \beta+2 \beta^{2}}\right|$. Because $2(\beta-1) \tau<2(2-\beta) \tau$ and $\left|1-4 \beta+2 \beta^{2}\right|>\left|1-6 \beta+2 \beta^{2}\right|$, so easy to get $\Delta x^{c}<\Delta x$. For the same reason, we have $\Delta x^{c^{*}}<\Delta x^{*}, \Delta r^{c}<\Delta r$ and $\Delta r^{c^{*}}<\Delta r^{*}$. Subtracted equation (28) by (11), we have $\Sigma x^{c}-\Sigma x=\frac{18(2 \beta-1)\left(2 A-2 c_{0}-\tau\right)}{\left(5-2 \beta+2 \beta^{2}\right)\left(7-4 \beta-2 \beta^{2}\right)}$ and subtracted equation (35) by (20), we get $\Sigma x^{c^{*}}-\Sigma x^{*}=\frac{\left(1-\beta+\beta^{2}+\beta^{3}\right) R-2(1-\beta)\left(A-c_{0}-0.5 \tau\right)}{1+\beta^{2}}$. So there exist the following relationships: $\left\{\begin{array}{ll}\Sigma x^{c} \leq \Sigma x, & 0<\beta<\frac{1}{2} \\ \Sigma x^{c} \geq \Sigma x, & \frac{1}{2}<\beta \leq 1\end{array}\right.$ and $\left\{\begin{array}{ll}\Sigma x^{c *} \leq \Sigma x^{*}, & 0 \leq \beta \leq \bar{\beta} \\ \Sigma x^{c^{*}} \geq \Sigma x^{*}, & \bar{\beta}<\beta \leq 1\end{array}\right.$.

Conclusions are therefore achieved and the proof is complete.

You-hua CHEN is lecturer of economics and marketing at college of economics \& management, South China Agricultural University, Guangzhou, P. R. China. He obtained his PhD from Institute of Industrial economics, Jinan University, China. Chen's research focuses on industrial organization, innovation and food safety. He has published several papers in the Economic Modelling, Agricultural Economics, Journal of Applied Mathematics, Ekonomska Istrazivanja - Economic Research.

Pu-yan NIE is a professor of industrial organization at Jinan University, Guangzhou, P. R. China. His research interests are industrial organization and game theory. Nie has published nearly 50 papers in SSCI/SCI journals such as European Journal of Operational Research, Journal of Economics, Journal of Computational Mathematics, Economic Modelling, etc.

X. Henry WANG is a professor of Department of Economics, University of Missouri-Columbia, USA. His research focuses onindustrial organization and game theory. Professor Wang has several papers published in national and international journals, such as Journal of Economics and Journal of Institutional and Theoretical Economics. 